\title{
Informing for Operations: The First Principia
}

\author{
Zbigniew J Gackowski \\ California State University Stanislaus, Turlock, CA, USA \\ ZGackowski@csustan.edu
}

\begin{abstract}
For more than 25 years, the framework of Ives, Hamilton, and Davis (1980) for research in computer-based (C-B) management information systems served hundreds of doctoral dissertations without yielding results of lasting validity. This paper summarizes the more lasting results from prior studies about the nature of informing for operations (whether human or robotic) as seen through the lens of decision-situation models. The model and framework of thinking about informing for operations entails fundamental concepts; basic distinctions; universal taxonomy of informing factors, their qualities, and priorities of their examination for research and practical applications; and quality requirements for factors in form and in substance. The paper summarizes the first identified principia. Informing and information, viewed physically, provides insights that clarify several controversial issues. This paper is presented to elicit challenge, critique, discussion, and suggestions in order to develop a mutual consensus among those dealing with informing.
\end{abstract}

Keywords: Informing, information, operation factors, model, framework, examination priorities, principia of informing.

\section{Foreword and Background}

Many streams of research deal with informing, a real interdisciplinary mix: cybernetics (a study of communication and control processes), operations research (analysis of processes for decision making), operations management, systems theory, systems analysis, praxiology (a study of human action with regard to effectiveness and efficiency), ethics, psychology, sociology, political science, etc. The $20^{\text {th }}$ century has become known as the century of the theory of relativity, quantum mechanics in physics, nuclear energy, electronics, aviation, computing, and space exploration. The $21^{\text {st }}$ century emerges at least as the century of information, microbiology, bioengineering, nano technology, and quantum computing.

Information - anything in form that can be communicated, similarly to factors in substance, operates among all of the at least partially autonomously acting entities. Information (broader knowledge as data, information, and rules of reasoning and proceeding) is a factor of power similar to other resources under one's control.

Material published as part of this publication, either on-line or in print, is copyrighted by the Informing Science Institute. Permission to make digital or paper copy of part or all of these works for personal or classroom use is granted without fee provided that the copies are not made or distributed for profit or commercial advantage AND that copies 1) bear this notice in full and 2) give the full citation on the first page. It is permissible to abstract these works so long as credit is given. To copy in all other cases or to republish or to post on a server or to redistribute to lists requires specific permission and payment of a fee. Contact Publisher@InformingScience.org to request redistribution permission.
Studies of the role of informing, information, and information quality shed a new light on many issues. Operations conducted by humans or robots depend on available or obtainable operation factors in substance or in form. In decision making, factors are represented by variables. Decision makers assume and act as if the knowledge available to them represents the reality they deal with. 
A wide spectrum of operations exists if assessed by complexity. At the lowest end, actions may be purely reactive to changes of the environment such as it occurs in physical inert objects and primitive forms of life. At the highest end, operations may follow sophisticated patterns of behavior or reasoning, which may be related to remote future goals and purposes of complex hierarchical systems that consist of interacting entities that may be complex on their own.

The more complex a system of operations is, the higher the level of making decisions, the fewer contacts decision makers have with factors of substance; and the higher their reliance is on factors in form, the less they are in direct contact with the reality they seemingly control. Political or corporate leaders actually act within a virtual reality of representations made available to them by others of influence; this was in antiquity and is now, with no visible end in the future.

Despite the virtual nature of such realities, information, informing, and operations are physical. They are subject to the same physical laws as the rest of the physical world. Operations conducted by humans also manifest aspects of a psychological, sociological, and political nature. This paper does not understate their significance but limits its scope. The physical aspects of data, information, knowledge, and informing in operations should be studied first. Only on top of solid physical foundations one may successfully add other aspects. Informing for operations offers an insight into the subject with results of lasting theoretical and practical validity. The explosive pervasiveness of computing and information technology has obscured the fact that the ultimate purpose of informing is to contribute to more effective and efficient operations. A broader view encompasses the role of information and informing in extending our knowledge and, subsequently, our control of the environment. This view deserves a separate study.

The presented approach to informing for operations is philosophically grounded in the Aristotelian approach to quality as distinguishing features, Schopenhauer's worldview as interplay between "will and representation," Nietzsche's perspectivism, the contributions of the pragmatists (Dewey and Pierce) to the theory of inquiry, and decision making with bounded rationality as defined by Simon (1956) and Kotarbinski (1961). It uses the concept of inertial frames borrowed from theoretical physics with the postulate of teleological relativity of views, observations, measurements, and assessments while, at the same time, accounting for the quantum nature of reality and the information that should map it one to one.

The physical approach to informing enables development of a model of informing for operations that encompasses basic distinctions, the main point of reference, observation points, observers, frame of reference, and a yardstick to measure results. The model and the related framework of thinking is described and presented at a level of abstraction that facilitates a formal definition of its concepts. The latter is necessary to avoid ambiguity in the light of the fundamental question of computer science: "What can be automated?" (Denning et al., 1989). Such an approach facilitates identification of the first universal principles that operate as fundamental laws - principia. It suggests a template for thinking, assessment, and prioritizing of the examination of factors for research and practical applications of informing, as defined by Cohen (1999), with the additions proposed by Gackowski (2007b). The purpose of this paper is to elicit challenge, critique, discussion, and suggestions in order to develop a mutual consensus among those dealing with informing.

For focused reading, key terms in paragraphs are in bold font, emphasis is in italics, highest emphasis is underlined, and terms followed by a definition are in bold italics. The more formal definitions, assumptions, and logical and mathematical expressions are numbered.

\section{Problem Statement}

The closest proxy of informing, alas without directly addressing it, is the "Framework for Research in Computer-Based (C-B) Management Information Systems," by Ives, Hamilton, and 
Davis (1980). It serves as the recognized framework for hundreds of doctoral dissertations in MIS.

Ives et al. (1980) claim that a major use of their framework is generation of relevant testable hypotheses for MIS research. The offered examples confirm Mendes' (2005) paper titled "The Poverty of Empiricism" (p. 189). Only four (1.2\%) of the 331 dissertations "specifically develop performance measures for the development, operations or use processes"; "descriptions have been over used and discovery research has been underutilized" (Ives et al., 1980, p. 930). For more than 25 years, their framework was used for hundreds of doctoral dissertations; nevertheless, only a few of them, if any, yielded research results of lasting validity in the discipline. A cursory survey of MIS textbooks seems to confirm it (Gackowski, 2007b).

Any model that is capable of becoming a rallying point for a broader community of researchers and of yielding research results of lasting validity should entail an explicitly or implicitly welldefined point of reference, observation point, and frame of reference. Research should not be limited to computer-based management information systems but, rather, should focus on how effectively and efficiently management is informed by whatever means. Such rigor is missing from the framework developed by Ives et al. (1980)

Informing and quality of factors in operations require a similar approach as practiced in theoretical physics where a rigorous approach begins with a well-defined point and frame of reference, a yardstick for measurements, and the postulate of perspectivism and relativity of observations.

Such an approach challenges many deeply ingrained views. As entirely novel, it yielded 17 scholarly publications at five different forums (ICIQ- 4, ISI- 5, IRMA- 3, DSI - 1, IJIQ - 1). Discussions revealed that research concerning management information systems (MIS), information quality (IQ), and informing for operations are insufficiently grounded in scientific principles. If quality of information and informing is not assured, it renders information technology ineffective and a wasted resource. Informing, as computing, serves human endeavors; it should be assessed from the same perspective. Such an approach, as presented below, offers insights that identify some universal fundamental principles of lasting validity (principia) in this domain.

\section{Introduction and Basic Definitions}

There exists a reality, whose basic aspects include objects, events, their attributes, and relationships. Within reality, competing subjects conduct purposive operations.

Operations are processes conducted by at least semi-autonomously acting humans, their organizations, systems controlled by artificial intelligence, or any combination thereof, although they may also include natural processes. Operations are triggered after a reflection and analysis of the situation. They are subject to the competitive, collaborative, and/or adversary will of the participants. Will is a sufficient reason for action.

Elements of reality may facilitate or inhibit operations. A factor is anything that affects results of operations. Factors may be in substance or in form.

- Factors in substance may entail the three known Ms (material, machinery, and manpower because methods are in form), products, services, energy, or weapons and means in warfare.

- Factors in form may entail methods, patterns, drawings, diagrams, schemas, or representation values of reality such as data or information (location, time, or elements of knowledge - rules in reasoning and proceeding).

Factors may be either available or not-yet-available.

- Available factors in substance are considered resources; those in form are data. 
- Not-yet-available (or uncertain) factors still must be acquired. They may be routine or non-routine.

- Routine factors are known by type and role; however, they must still be acquired or gathered. If in form, they constitute routine information.

- Non-routine factors are still unknown or unrecognised but of potential significance, such as a new invention, material, tool, or device. If in form, they constitute non-routine information. In operations, both are of a strategic nature and should be assessed separately.

Processes are partially ordered networks of state transitions or transformations of factors. They may be represented by graphs. One distinguishes processes that are natural and by design. Natural processes may be inert or evolving like life processes. They differ by the type of their input and the types of components they require to occur.

- Natural inert processes to be triggered and to happen require input factors subject to transformation and energy.

- Natural evolving processes require information that triggers them and controls their evolution (seeds, DNA).

- Processes by design require information about their design, and/or required by their design, means of work (tools, equipment, etc.), control, management, and work force. With the advances or technology and automation, workforce is gradually being displaced by more and more sophisticated means of work and robotic devices controlled numerically or more by artificial intelligence that extends their design. Process by design that requires human work is called ergo-transformation process.

In all processes, state transitions are oriented toward specific outcomes (not goals, objectives, or purposes, which are human categories, never intrinsic qualities of processes). Hence, they form a graph structure as defined in the theory of sets.

Business processes are processes by design that transform factors from their initial states to their output states. They need information about their design and for their control and management. The latter require continuous informing - the flow of feedback and control information.

Informing may and usually requires data and information processing. The latter are processes by design that also transform factors from their initial states to their output states, but these transformations are limited to state transitions of marks on the processed substance - the carrier. The nature of marks is symbolic. (Mark - "Something that signals the existence of something else: indication, earmark, evidence, notice, sign, symptom, token, trace, warning, clue, foretoken, hint, signal, mark, suggestion" - Excerpted from American Heritage Talking Dictionary. Copyright () 1997 The Learning Company, Inc. All Rights Reserved). Hence, marks are factors in form for potential use and/or replication, not to transform the carrying substance (paper, magnetic tape, disk, or electrons with regard to their spin in quantum computing) by them.

Operations must be managed. Management plans, organizes, motivates, directs, supervises, monitors, and controls operations. We need to make the following distinctions:

- Routine management is charged with maintaining the current status of operations;

- Tactical management is charged with adjusting operations according to the perceived changes of reality, with the exception of evaluation criteria, the executive decision maker, and the purpose; 
- Strategic management determines the main purpose of operations, the criteria of effectiveness and efficiency, and the chief executive decision maker.

Managers are the driving force. They are the observing, participating, and interested decision makers with a purpose P, as viewed by John Dewey (Magee, 2000) in his theory of inquiry, which serves as the main point of reference. They act within a specific frame of reference (circumstances the operations are subject to).

Definition 1: Frame of reference is based on the available knowledge. It consists of

- $\quad \mathbf{S N}$ - a set of variables (sn $\mathbf{\epsilon} \mathbf{S N}$ ) that represent significant states of nature and are beyond control of decision makers - independent variables such as weather conditions;

- $\quad \boldsymbol{D}$ - a set of dependant variables (d $\mathbf{E} \mathbf{D}$ ) of significant materiality that are under decision-makers' control, such as to use or not to use a toll road for trucking;

- An adopted criterion of effectiveness and efficiency, such as return on equity.

Assumption 1: Decision-makers employ

- Mainly rational and rule-following choices, as defined by March (1994);

- With bounded rationality,

○ as defined by Simon (1956) with regard to limitations of cognition, and

○ as proven by Kotarbinski (1961, pp. 189-201) from the opposite perspective that perfect rationality is unattainable (if rigorously pursued, it leads to a logical paradox that precludes any action);

- Prevention of irrational choices that may qualitatively change the situation; and

- Automatic arbitration for resolving choice uncertainty in dynamic situations, as defined by Denning (2007). (It is impossible to make an unambiguous choice between nearsimultaneous events under a deadline).

Assumption 2: Measurability of the main purpose $\mathbf{P}$ and the results of operations denoted RO. The measure of the results denoted $\mathbf{M}_{\mathbf{R O}}$ is a function of the main purpose $\mathbf{P}$, the sets $\mathbf{S N}$ and $\mathbf{D}$, formally: $M_{R O}=M_{R O}(P, D, S N)$.

Definition 2: Materiality M(e) of entity $\boldsymbol{e} \boldsymbol{\epsilon} \boldsymbol{E}$ is measured by the difference in the measure of results $\mathbf{M}_{\mathbf{R O}}$, when operations are conducted with and without the entity e, formally

$$
M(e)=M_{R O}(E)-M_{R O}(E-e)
$$

Definition 3: $E$ is a set of materially significant entities e $\mathbf{E} \mathbf{E}\{$

- factors in substance or in form (here, mainly data and information items) f $\mathbf{e ~ F}$

- tasks $\mathbf{t} \mathbf{\epsilon} \mathbf{T}$

- variables v e V

- relationships among them $\mathbf{r}\left(\mathbf{e}^{\prime}, \mathrm{e}^{\prime \prime}\right) \mathbf{\epsilon} \mathbf{R}\left(\mathbf{E}^{\prime}, \mathbf{E}\right.$ ')

- qualities q(e) $\mathbf{\epsilon} \mathbf{Q}(\mathbf{E})$

- properties - states of qualities $\mathbf{s}(\mathbf{q}(\mathbf{e})) \mathbf{E} \mathbf{S}(\mathbf{Q}(\mathbf{E}))$, or

- incremental changes of their states $\left.\Delta \mathbf{s}(\mathbf{q}(\mathbf{e}))=\mathbf{s}^{\prime \prime}(\mathbf{q}(\mathbf{e}))-\mathbf{s}^{\prime}(\mathbf{q}(\mathbf{e}))\right\}$,

if the absolute || difference of the results of operations $\mathbf{M}_{\mathbf{R O}}$ when conducted with and without them is not less than the threshold of significance - the minimal increment $\mathbf{S}_{\text {min }}\left(\Delta \mathbf{M}_{\mathbf{R O}}\right)$ or materiality $\mathbf{M}(\mathbf{e})$ determined by the policy of the decision maker, formally

$$
\Lambda\left[\left|\mathbf{M}_{\mathbf{R O}}(\mathbf{E})-\mathbf{M}_{\mathbf{R O}}(\mathbf{E}-\mathbf{e})\right| \geq \mathbf{S}_{\min }\left(\Delta \mathbf{M}_{\mathbf{R O}}\right)\right] \text { for all e } \epsilon \mathrm{E} \text {, or }
$$




\section{$\Lambda\left[|M(e)| \geq S_{\min }\left(\Delta \mathbf{M}_{R O}\right)\right]$ for all e $\epsilon \mathrm{E}$}

Symbolic representations of operation factors and relations among them constitute the decision-maker's knowledge. In this context, knowledge is what one knows or, broader, what society knows and what is available. It is represented by the available data values, the significant relationships among them, and rules of procedure in reasoning and proceeding, including sequences of state transitions of robots. What one does not know, one tries to learn (collect, acquire, recognize). New information, new relationships, and new rules of procedure are added to what was known before and what has been learned and recognized as valid or at least acceptable. Thus grows the body of knowledge of individuals, organizations, and societies.

The initial version of a decision-situation model is also based on the knowledge available to managers - decision makers. Factors are subject to changes that reflect the changing reality. A monitoring system must be established for the decision makers to remain current. In routine operations, collection of representations from the monitored reality takes place for all the known and rather well-established variables, which represent factors that significantly impact operations and their results. Such representations describe a relatively stable picture of routine operations whose quasi-equilibrium is subject to disturbances.

When viewed from the perspective of communications, the incoming representations (factors in form) may be associated with a zero or none-zero amount of information, as defined by Shannon and Weaver (1949). Those with a zero amount of information are already available or known, hence data. Among representations with a non-zero amount of information, one may make the following distinctions:

- Routine information about changes of known factors changes the situation mostly quantitatively (i.e., usually minor adjustments) unless the quantitative changes reach a critical point, causing qualitative changes (i.e., a major discrete change - evaporation, melting).

- Non-routine information about new significant, not-yet-recognized, or non-routine factors always qualitatively and quantitatively changes the affected situation. It is subject to strategic management and decision making and should be considered separately.

Table 1 A general taxonomy of situation-specific elements of knowledge about operations

\section{K N O W L E D G E}

- a symbolic representation of reality in operations (objects, events, their identifiers and attributes, relations among them, and rules of procedure in reasoning and proceeding)

\section{$\underline{\text { D A T A }}$}

Representations about the given, known, available, assumed-true operation factors; they can never change the existing decision situation - the status quo.

\section{IN F ORMATION}

Representations about the unknown or uncertain operation factors, not yet available, still to be acquired and always associated with a none-zero amount of information, as defined by Shannon and Weaver (1949)

\section{$\underline{\text { Routine Information }}$}

reflects changes about known operation factors, usually causing only quantitative changes of results; they are the subject of routine operational and tactical management.

\section{$\underline{\text { Non-routine Information }}$}

about still unknown factors, which, if significant, always result in qualitative changes of the existing decision situation; they are the subject of strategic management. 
From the viewpoint of those who manage routine operations, the collected representations are either

- Routine data values only, because no changes affecting the status quo have taken place, or

- Routine information values, because changes have taken place.

All of the above represent the knowledge about the situation and are summarized in Table 1.

\section{Basic Concepts of Decision Situations}

There is a vast theory and practice of decision making. Decision-making situations must be described and defined, which different types of modeling accomplish. In human evolution the first were physical models, followed by descriptive models, schematic models, and, finally, mathematical models, all of which are used to represent and simulate a fragment of reality under consideration. There are two distinctively different decision-making frameworks: qualitative and quantitative.

In qualitative frameworks, the definitions of decision situations are usually descriptive, vague, and fuzzy. They pertain to cases that are unique, even without a historic precedence. Usually they emerge at the highest strategic level of decision making. Qualitative descriptions may refer to moral, social, political, corporate, community, and personal values, the legal environment, precedence, even to emotions and historical analogies, etc. One deliberately avoids quantitative considerations. It is said that such definitions are unstructured or ill structured. Despite the deficiencies, the qualitative aspects must be considered first, for their consequences are strategic, farreaching, long term, and serious.

In quantitative frameworks, the definitions of decision situations are usually precise, unambiguous, mathematical, and with measurable results. Usually they pertain to tactical and operational levels of decision making that convert strategic decisions into detailed action plans. They call for measurements, statistical analysis, or simulation. Such decision situations are well structured. Contrary to nonprofessional expectations, despite the accuracy and precision, the consequences of choices with quantitative models are usually temporary, short term, and of limited scope. However, when applied under the same set of circumstances, they produce the same results.

\section{Components of decision situations entail}

1. possible states of the situation $\mathbf{s n}_{\mathbf{j}}$ - independent variables

2. potential choices or decision options $\mathbf{d}_{\mathbf{i}}$ - dependent variables

3. foreseen outcomes $\mathbf{0}_{\mathbf{i j}}$ for the respective pairs of the above

4. utility values $\mathbf{u}\left(\boldsymbol{o}_{\mathrm{ij}}\right)$ assigned to outcome $\mathbf{o}_{\mathbf{i j}}$ by a utility function

5. evaluation criteria of the outcomes

6. decision makers, and, finally,

7. the main purpose $\mathbf{P}$ of operations.

They are listed in ascending order of the expected extent of pervasiveness of their changes.

Outcomes $\mathbf{0}_{\mathbf{i j}}$ are rarely simple variables. They represent the current, foreseen, or attained state of reality in its significant aspects. They may represent nothing more than a simple change in cost or two dramatically different pictures of a scene before and after an accident, a village before and after a tornado hit, or a field before and after battle. Thus, the outcome $\mathbf{0}_{\mathbf{i j}}$ is represented as a one- 
dimensional array of states of all significant aspects of reality, which are projected when decision $\mathbf{i}$ has been implemented in the state of nature $\mathbf{j}$.

For decision makers, an incoming symbolic representation of reality that

- matches the state of the model does not change it, its entropy, and conveys zero amount of information; it is the given, available - the datum.

- does not match the current state of the model and conveys a non-zero amount of information and changes the model; it is the communicated meaningful information $\Delta I$.

Decision situation specification matrices (Table 2) are also built based on the available knowledge. At first, they offer purely static pictures. The monitored changing reality (the system and its environment), however, requires a continuous adjusting of at least some of the major components of the model. The type, number, and degree of the changes is induced not only be the changing environment but also by the decision maker, who adjusts the way he or she views the situation and reacts in response. A decision-situation matrix serves here as the lens through which one may track the factors' operation meaning, materiality, and pervasiveness of their changes.

Table 2 Decision-situation specification matrix

\begin{tabular}{|c|c|c|c|c|c|c|c|}
\hline $\begin{array}{l}\mathrm{j}[1 . . . \mathrm{m}] / \\
/ \mathrm{I}[1 . . \mathrm{n}]\end{array}$ & $\begin{array}{l}\mathrm{P}_{1} \\
\mathrm{Sn}_{1}\end{array}$ & $\begin{array}{l}\mathrm{P}_{2} \\
\mathrm{Sn}_{2}\end{array}$ & $\begin{array}{l}\cdots \\
\cdots\end{array}$ & $\begin{array}{l}\text { probabilities }_{j} \\
\text { states }_{j}\end{array}$ & $\begin{array}{l}\cdots \\
\cdots\end{array}$ & $\begin{array}{l}\mathbf{p}_{\mathrm{m}-1} \\
\mathbf{S n}_{\mathrm{m}-1}\end{array}$ & $\begin{array}{l}\mathbf{p}_{\mathrm{m}} \\
\mathbf{s n}_{\mathrm{m}}\end{array}$ \\
\hline $\mathrm{d}_{1}$ & $\mathbf{u}\left(\mathbf{o}_{1,1}\right)$ & $\mathrm{U}\left(\mathbf{0}_{1,2}\right)$ & $\ldots$ & $\cdots$ & $\ldots$ & $\mathrm{U}\left(\mathbf{o}_{1,1-1}\right)$ & $\mathrm{U}\left(\mathbf{0}_{1, \mathrm{~m}}\right)$ \\
\hline$d_{2}$ & $\mathbf{u}\left(\mathbf{o}_{2,1}\right)$ & $\mathbf{u}\left(\mathbf{o}_{2,2}\right)$ & $\ldots$ & $\ldots$ & ... & $\mathbf{u}\left(\mathbf{o}_{2, \mathbf{m}-1}\right)$ & $\mathbf{u}\left(\mathbf{o}_{2, \mathrm{~m}}\right)$ \\
\hline & $\ldots$ & \multicolumn{4}{|c|}{$\cdots$} & $\ldots$ & $\cdots$ \\
\hline decisions $_{i}$ & $\ldots$ & \multicolumn{5}{|c|}{$\begin{array}{l}\text { Utility values of outcomes } o_{i j}: \quad u\left(o_{i j}\right) \text {, } \\
\text { where } u-a \text { utility function }\end{array}$} & $\cdots$ \\
\hline ... & $\ldots$ & & & & & & $\cdots$ \\
\hline$d_{n-1}$ & $\mathrm{u}\left(\mathbf{o}_{\mathrm{n}-1,1}\right)$ & $u\left(o_{n-1,2}\right)$ & ... & $\ldots$ & ... & $\mathbf{u}\left(\mathbf{o}_{\mathrm{n}-1, \mathrm{~m}-1}\right)$ & $\mathbf{u}\left(\mathbf{o}_{\mathrm{n}-1, \mathrm{~m}}\right)$ \\
\hline$d_{n}$ & $\mathrm{u}\left(\mathbf{o}_{\mathrm{n}, 1}\right)$ & $\mathbf{U}\left(\mathbf{o}_{\mathbf{n}, 2}\right)$ & ... & ... & ... & $\mathbf{u}\left(\mathbf{o}_{\mathbf{n}, \mathbf{n}-\mathbf{1})}\right.$ & $\mathbf{U}\left(\mathbf{o}_{\mathbf{n}, \mathbf{m}}\right)$ \\
\hline
\end{tabular}

Changes $\Delta$ of independent variables sn e SN and probabilities p є $\mathbf{P}$ are viewed as the difference between their respective previous (") and current states (') caused by incoming factors $\Delta \mathbf{F}$, here mainly information $\Delta \mathbf{I}$, defined respectively as $\Delta \mathbf{s n}(\Delta \mathbf{F})=\mathbf{S N}$ ' - SN' and $\Delta \mathbf{p}(\Delta \mathbf{F})=\mathbf{P}$ ' - P'. They invariably change the affected outcomes $\mathbf{0}_{\mathrm{ij}} \mathbf{\epsilon} \mathbf{O}$, their utility $\mathbf{u}_{\mathrm{ij}} \mathbf{\epsilon} \mathbf{U}$, and results of operations $\mathbf{M}_{\mathbf{R O}}$. Subsequently however, decision makers may also change their tactic and select different decision options from d', to d"'. Summarily, they change the total outcome $\Delta \mathbf{o}(\Delta \mathbf{F})$ equal to the difference between the two arrays - the previous outcomes and the current outcomes, where

Definition 4: $\Delta \mathbf{O}(\Delta \mathbf{F})=\mathbf{O}$ " $-\mathbf{O}$ ' is the operation meaning of the incoming factors $\Delta \mathbf{F}$, whether of substance or in form (then information $\Delta \mathbf{I}$ ), as viewed by the cofounder of pragmatism Peirce (1958), the father of verifiability theory of the meaning, while

Definition 5: $\Delta \mathbf{M}(\Delta \mathbf{F})=\mathbf{M}_{\mathbf{R O}}\left(\mathbf{O}^{\prime \prime}\right)-\mathbf{M}_{\mathbf{R O}}\left(\mathbf{O}^{\prime}\right)$ is the materiality of the incoming factor $\Delta \mathbf{F}$ or information $\Delta \mathbf{I}$. The utility function $\mathbf{u}$ assigns different utility values to the respective differences with regard to each aspect of reality in conformance with Assumption 3.

Assumption 3: The postulate of teleological perspectivism and general relativity of assessments. Any aspect of operations is viewed, perceived, and assessed the same way unless the pur- 
pose and the frame of reference change. Nevertheless, when a change occurs, it changes how even the physically identical entities are viewed by decision makers. This is an all-pervasive principle in informing for operations. It is analogous to the concept of inertial frames in theoretical physics (Principium 1).

In rigorous studies, the smallest distinguishable element subject to inquiry must be defined. The emergence of nano-technology, quantum computing, molecular bioengineering, and so on indicates our will to reach down to the naturally elementary. It may be an act of exchange of goods in economy, transaction in business, movement by a robot, human action, or behavior of a particle down to the submicroscopic systems of the minimum observable. It is restricted to a natural set of discrete values such as the number of the elementary amount of action - the Planck's constant ("Plank's constant," 2007). With new technologies, the size of significant changes decreases precipitously.

The low limits of changes are usually determined by the state of measurement technology (methods, tools, and means). Hence, information that one to one maps changes of reality must fully account for the relativity of all observations and assessments of the impact of informing in operations and its quantum nature for storing, communicating, and acting (Principium 2). Changes may impact the entire model of operations, the decisions made, and their implementation; however, it is assumed that any of them must cause a significant change in the measure of the results of operations with regard their purpose in light of the adopted criterion of assessment.

\section{Informing for Operations}

Science requires a clear distinction and definition of the subject and the objects subject to inquiry. In informing, symbolic representations of reality with the controversial notion of information play a key role. In common use, information denotes communicated symbolic representation - a factor in form, whether understood, useful, or not. Entities communicate by passing symbolic representations. For those receiving them, they should be unknown or at least uncertain to be considered information.

Symbolic representations of reality already available are considered the given, known data. Data processing, as a deterministic process in its nature, can never yield any amount of information or anything unknown that could not be inferred from data. Nevertheless, one may present data in a more usable, effective, and efficient manner for users. A well-designed presentation of data may reduce errors and increase efficiency of operations. A clear recognition of the dichotomous nature of what is available and not yet available or data and information (Principium 9) is not common despite the fact that difference is tangible and can be tested in any decision situation and any decision support system (DSS). Thus it is of universal validity (Gackowski, 2006a). It should forever ban fuzziness in this respect; however, errors not only in information but also in data may become deadly as well (Fisher, Chengalur-Smith, \& Wang, 2006, p. 5). Exploration of vast collections of data may yield something unknown. This, however, constitutes data mining, which is research, a quest for something unknown that is not part of routine data processing.

Communicated symbolic representations of reality may mean changes or not. Information denotes only symbolic representation that is uncertain or unknown to its recipients that/who control operations and its environment. The ultimate intrinsic (naturally belonging to it) purpose of informing, whether acknowledged or not, is to extend one's control. Information and knowledge, similarly as resources in substance, are paramount factors of power. Among living entities, all communication, all informing is purposive, and biased, tainted by purpose that undermines its objectivity. An additional source of bias is ignorance of senders and recipients of information. Informing always yields a wide spectrum of different degrees of misinformation, with two excep- 
tions at opposite extremes: valid information and its opposition, perfect disinformation. Practically we deal with

- the less-than-perfect disinformation that intentionally deceives (perfect disinformation as being to obvious would defeat the intended deception);

- misinformation, which unintentionally misrepresents reality;

- valid information, which maps reality faithfully one to one into a communicated symbolic representation.

The exceptional nature of valid information necessitates creation of institutions and services that are based on trust that the provided data and information are credible. Misinformation and disinformation require the establishment of counter measures, including counter intelligence.

Informing entities may be active or passive. Passive informing entities are real objects and processes that yield information when observed, examined, counted, and/or measured. Active informing entities - sources - by their nature or by design transmit, disseminate, or broadcast signals that may convey information. Some of the above entities may be widely known and easily identifiable; others are completely unknown to the entities informed. Active-by-design informing entities such as senders or disseminators of information (educators, advertisers, professional information providers, politicians, preachers, etc.) try to affect the entities informed according to their purpose. Some of the informing may even be enforced (mandatory education or re-education camps), while most of it is not. Active-by-design informing is the vast field of communications.

Communication channels link informing entities with entities informed. In communication channels, transformations of signals constitute the informing processes that always are subject to distortions such as tapping, interference, etc. (Principium 3). Informing may be solicited and unsolicited. The links may be direct or indirect, which leads to direct or indirect informing. In direct informing, information flows directly between the informing entities (sources) and the entities informed (face to face in human contacts). In indirect informing, intermediary manipulation of information occurs between informing entities and entities informed.

Within complex active-by-design informing entities and complex active entities informed, the division of labor leads to specialized subentities that deal with information collection, acquisition, recognition, storing, processing, and presentation, where data are organized in databases and/or data warehouses. They are specialized data and information delivery systems.

Entities informed (receiving clients, students, users, decision makers) may also be active or inactive. The active ones (marketing prospects, competitors, adversaries, voters, public, robotic devices, etc.) must autonomously conduct some operations so that informing may make them behave differently than they would otherwise. Entities informed might be simple or composite entities, individuals, or organizations; they might even be robotic devices that are controlled simply numerically or as a function of applied artificial intelligence. Initially, when viewed from the outside, the effect of informing on the inactive entities informed may not be noticeable for a long time but in the long run may become significant once they later act as the result of upbringing, education, training, indoctrination, or programming. Entities informed may be targeted intentionally by disseminators of information, or they may actively gather information from sources. Hence, they may be interested in being provided with some information products or services. They may pay for being informed or seek only information that is offered seemingly free. They may also be inclined to enter into a dialog to refine the informing process to their advantage.

There are two universal conditions for effective informing:

1. For informing to take place, there must be a difference in states of the informing entity and the entity informed with regard to the transmitted signals. In communications theory, 
the difference is measured by entropy. (Entropy - a measure of the disorder or randomness in a closed system that consists of the informing entity (source) and the entity informed (client) or the number of bits necessary to transmit a message as a function of the probability that the message will consist of a specific set of symbols.) The difference cannot be smaller than the smallest amount of action. With no difference in the states of informing entities (sources) and the entities informed (users) (because they know the same, they are in the same state), their respective levels of entropy are equal. After informing has occurred, the respective states at the extreme ends of the communication channels become equal, and their joint entropy increases. When such a change occurs, the received representation is not known by the entity informed before informing occurs.

2. Informing in operations makes sense as much as it impacts actions and, subsequently, the results, either immediately or after a delay. To be effective, information must be operation usable and effectively operationally complete to trigger a transition of the state of operations (to act or not). From the perspective of entities informed, after informing, the gathered information become the operating entities' data and recognized elements of knowledge that update their common databases and knowledge bases.

In contrast to Shannon and Weaver's (1949) mathematical theory of communication based on assumption of probabilities, Mazur's approach (1970) is grounded in associations of discrete signals. At its limits, when the number of associations is infinitely large, it yields exactly the same formulas as proposed by Shannon and Weaver. Thus, Mazur's model provides the ultimate insight into the internal mechanics of communications and control, it confirms the former, it is broader, it accounts for more aspects, it applies to situations where there is little or no room for stochastic considerations, and it makes the amount of information discrete and countable.

\section{Quality of Operation Factors}

The initial definitions of quality are general. They are based on the Aristotelian approach to quality as something that enables one to distinguish and define objects. Later, the definitions will be expanded to accommodate aspects of the quality of factors that are necessary and useful in operations.

Definition 6: Generally, quality - $\boldsymbol{Q}$ is an infinite set $\{\ldots\}$ of quality attributes (essential and distinctive characteristics), simply called qualities $\mathrm{q}_{\mathrm{i}}$ :

$$
Q=\left\{\mathbf{q}_{1}, \mathbf{q}_{2}, \ldots \mathbf{q}_{\mathbf{i}}, \ldots \mathbf{q}_{\infty}\right\}, \text { where } \mathbf{i} \text { belongs to a set of ordinal numbers i } \mathbf{\epsilon}\{\mathbf{1}, \mathbf{2}, \ldots \infty\}
$$

Definition 7: A distinguishing quality - $Q_{D}(\mathbf{E})$ of the class $\mathbf{E}$ of entities e $\mathbf{E} \mathbf{E}$ (cutting tools - factors of substance, aerial pictures - factors in form) is a finite set of necessary qualities $\mathbf{n q}_{\mathbf{i}}(\mathbf{E})$ (length - cutting edge, number of dots per inch - resolution of a picture) of cardinality $\mathbf{k}=$ $\|(\mathbf{n q}(E)) \mid: Q_{D}(E)=\left\{\mathbf{n q}_{1}(E), \mathbf{n q}_{2}(E), \ldots \mathbf{n q}_{\mathbf{i}}(E), \ldots \mathbf{n q}_{\mathbf{k}}(E)\right\}$

Definition 8: $\boldsymbol{Q}(\boldsymbol{e})$ is the quality of the entity $\boldsymbol{e}$ (tool, data value) defined by a vector of states $\mathbf{s}_{\mathbf{j}}(\mathbf{q}(\mathbf{e})$ ) (operational or non-operational for a device, usable or not for a data value) of necessary qualities nq(e) $\mathbf{E} \mathbf{N Q ( e ) ~ ( s h a r p n e s s ~ o f ~ a ~ t o o l , ~ c r e d i b i l i t y ~ o f ~ a ~ d a t a ~ v a l u e ) ~ a n d ~ o t h e r ~ q u a l i t i e s ~ o q ( e ) ~}$ c OQ(e) (acquisition cost). Of course, $\mathbf{Q}(\mathbf{e})=\mathbf{N Q}(\mathbf{e}) \cup \mathbf{O Q}(\mathbf{e})$. Formally,

$$
Q(e)=\left[\mathrm{s}\left(\mathrm{q}_{1}(\mathrm{e})\right), \mathrm{s}\left(\mathrm{q}_{2}(\mathrm{e})\right), \ldots \mathrm{s}\left(\mathrm{q}_{\mathrm{j}}(\mathrm{e})\right), \ldots \mathrm{s}\left(\mathrm{q}_{\mathrm{n}}(\mathrm{e})\right)\right] \text { for all } \mathrm{q}(\mathrm{e}) \in \mathrm{Q}(\mathrm{e}) \text { of cardinality } \mathrm{n}=\|\mathrm{Q}(\mathrm{e})\| .
$$

Any quality $\mathbf{q}(\mathbf{e})$ of entity $\mathbf{e}$ can take on one out of two or more distinguishable states $\mathbf{s}_{\mathbf{j}}(\mathbf{q}(\mathbf{e})) \mathbf{\epsilon}$ $\mathbf{S}(\mathbf{q}(\mathbf{e}))$ of their qualities $\mathbf{q ( e )} \mathbf{e} \mathbf{Q}(\mathbf{e})$ of entity e $\mathbf{\epsilon} \mathbf{E}$, where $\mathbf{j} \mathbf{\epsilon}\{\mathbf{1}, \mathbf{2} \ldots \mathbf{n}\}$ and cardinality $\mathbf{n}=$ $\|\mathbf{S}(\mathbf{q}(\mathbf{e}))\|$, which is always greater than 1. A set of states $\boldsymbol{s}(\boldsymbol{q}(\boldsymbol{e}))$ of quality $q(\boldsymbol{e})$ can be Boolean \{true, false\}, defined by enumeration, or an ordered set of numbers. The last implies measurability and ranking of these states (calibre of fire arms). 
Definition 9: Correspondingly, quality requirements $Q R(e)$ (type, size, color, cost, etc.) for a specific entity e are defined by a vector of required states $\operatorname{rs}(\mathbf{q}(\mathbf{e})) \mathbf{\epsilon} \mathbf{R S}(\mathbf{q}(\mathbf{e}))$. Formally,

$$
Q R(e)=\left[\mathbf{r s}\left(\mathbf{q}_{1}(\mathbf{e})\right), \operatorname{rs}\left(\mathbf{q}_{2}(\mathbf{e})\right), \ldots \operatorname{rs}\left(\mathbf{q}_{\mathbf{n}}(\mathbf{e})\right)\right] \text { for all } \mathrm{q}(\mathrm{e}) \in \mathrm{Q}(\mathrm{e}) \text { and } \mathrm{n}=\|\mathrm{Q}(\mathrm{e})\| \text {. }
$$

Qualities acquire their significant materiality from the situation (purpose, circumstances, and adopted criterion of effectiveness) to which they apply, while the entities possessing those qualities acquire their significant materiality from their qualities. To this end, factors must meet adequate quality requirements determined by the situation.

Assumption 4: M(e) - Materiality of an entity $e$ is a function $f$ of the significant states $s(q(f))$ of all significant qualities $\mathbf{q}(\mathbf{e}) \mathbf{e} Q(\mathbf{e})$ of the significant entity e, formally, $\boldsymbol{M}(\boldsymbol{e})=\boldsymbol{f}(\mathrm{S}(\mathbf{q}(\mathbf{e}))$ for all significant states $\mathbf{S}$ of significant qualities $\mathbf{q}$.

Assumption 5: Materiality $M(s(q(e)))$ of any state $\mathbf{s}$ of any quality $q$ of any entity $\mathbf{e}$ is subject to the law of diminishing returns ("Diminishing returns," 2007), hence any quality q of any entity e should be used at its optimum or acceptable level. Subsequently, it implies that there is no quality $\mathbf{q}$ that monotonically improves the measure $\mathbf{M}_{\mathbf{R O}}$ of the operation results $\mathbf{R O}$.

Definition 10: Significant operation quality $Q(f)$ of a factor $f \epsilon F$ is defined by the significant states of its significant qualities $\mathbf{q ( f )} \mathbf{e} \mathbf{Q}(\mathbf{f})$ that qualify it to play a significant role in operations. These states $\mathbf{s}(\mathbf{q}(\mathbf{f}))$ e $\mathbf{S}(\mathbf{Q}(\mathbf{f}))$ of the vector should be distinguishable and significant with regard to the results of operations. In general, significant quality can be represented as a vector of significant states of the component qualities in a multidimensional space. (In research, necessary distinguishing qualities of entities facilitate compression of knowledge and mastering its complexity.) Formally, significant quality of a significant factor later called factor's quality is a vector of significant states s, later called simply states:

$$
Q(f)=\left[\mathbf{s}\left(\mathbf{q}_{1}(\mathbf{f})\right), \mathbf{s}\left(\mathbf{q}_{2}(\mathbf{f})\right), \ldots \mathbf{s}\left(\mathbf{q}_{\mathbf{i}}(\mathbf{f})\right), \mathbf{s}\left(\mathbf{q}_{\mathbf{n}}(\mathbf{f})\right)\right] \text { for all } \mathrm{q}(\mathrm{f}) \in \mathrm{Q}(\mathrm{f}) \text { of cardinality } n=\|\mathrm{Q}(\mathrm{f})\|
$$

Definition 11: The state $s$ (not a measure) of quality $Q$ of operations $O-s(Q(O)$ ) is defined by a set $\mathbf{S}_{\mathbf{Q v}}$ of significant quality vectors qv $\mathbf{\epsilon} \mathbf{S}_{\mathbf{Q v}}$ with regard to all significant qualities $\mathbf{q ( f )} \mathbf{\epsilon} \mathbf{Q}(\mathbf{f})$ of all significant factors $\mathbf{f} \mathbf{\epsilon} \mathbf{F}$ with regard to the purpose $\mathbf{P}$ with the threshold of significance $\mathbf{S}_{\min }\left(\Delta \mathbf{M}_{\mathbf{R O}}\right)$ effective in significant states of nature $\mathbf{S N}$. Formally, it is an ordered septet $\boldsymbol{s}(\boldsymbol{Q}(\boldsymbol{O}))$ : $=\left\langle\mathbf{M}_{\mathrm{RO}}, \mathbf{P}, \mathbf{S}_{\min }\left(\Delta \mathbf{M}_{\mathrm{RO}}\right), \mathbf{F}, \mathbf{Q}(\mathbf{F}), \mathbf{S}_{\mathbf{Q V}}, \mathbf{S N}>\right.$ where

- $\quad \mathbf{M}_{\mathbf{R O}}=\mathbf{M}_{\mathbf{R O}}[\mathbf{P}, \mathbf{s}(\mathbf{q}(\mathbf{f})), \mathbf{S N}]$ for all $\mathrm{s}(\mathrm{q}(\mathrm{f})) \in \mathrm{S}(\mathrm{Q}(\mathrm{f})), \mathrm{q}(\mathrm{f}) \in \mathrm{Q}(\mathrm{f})$, and $\mathrm{f} \epsilon \mathrm{F}$ is a measure of the results of operations

- $\quad \mathbf{P}$ - the purpose of operations

- $\mathbf{S}_{\min }\left(\Delta \mathbf{M}_{\mathbf{R O}}\right)$ - the threshold of significance expressed as the smallest increment of $\Delta \mathbf{M}_{\mathbf{R O}}$

- $\quad \mathbf{F}$ - set of significant factors $\mathbf{f}$

- $\mathbf{Q}(\mathbf{F})$ - sets of significant qualities $\mathbf{q ( f )} \mathbf{\epsilon} \mathbf{Q}(\mathbf{f})$ for all $f \in F$

- $\mathbf{S}_{\mathbf{Q v}}-$ set of vectors $[\mathbf{s}(\mathbf{q}(\mathbf{f}))]$ of significant quality states $s(q(f)) \in S(q(f))$ of significant qualities $q(f) \in Q(f)$ of significant factors $f \in F$

- $\quad \mathbf{S N}$ - a set of significant states of nature (beyond the decision-maker's control)

The goal is to obtain the optimal or acceptable results of routine operations $\mathbf{O}$ assessed by a selected measure $\mathbf{M}_{\mathbf{R O}}$ by identifying the optimal or acceptable states $\mathbf{S}_{\text {opt/acc }} \mathbf{E} \mathbf{S}_{\text {opt/acc }}$ for all significant qualities of all significant factors. Quality requirements can be satisfied at the optimum, acceptable but suboptimal, or unacceptable level, or even left undefined. In summary, one can measure quality only indirectly by its impact on results, not by the states of quality as practiced in empirical studies and industrial applications of Total Quality Management (TQM or TDQM). 
Definition 12: In operations, any $(\boldsymbol{\Lambda})$ significant state $\mathbf{s}$ of significant quality $\mathbf{q}$ of significant factor $\mathbf{f}$ in a situation defined by a vector of significant states of nature $\mathbf{S N}$ with regard to purpose $\mathbf{P}$ by a selected criterion $\mathbf{M}_{\mathrm{RO}}$ are the optimal or acceptable state $\boldsymbol{s}_{\text {optacc }}$ when the results are optimal or acceptable (OPT/ACC): $\boldsymbol{\Lambda}\left[\mathbf{s}(\mathbf{q}(\mathbf{f}))=\mathbf{s}_{\text {opt/acc }}(\mathbf{q}(\mathbf{f}))\right.$ when $\left.\mathbf{M}_{\mathbf{R O}}(\mathbf{s}(\mathbf{q}(\mathbf{f})))=\mathbf{O P T} / \mathbf{A C C}\left(\mathbf{M}_{\mathbf{R O}}\right)\right]$ for all $s \in S(q(f)), q(f) \in Q(f)$, and $f \in F$. A vector of such states defines by enumeration the optimal or acceptable state of quality of operations.

Definition 13: The optimal or acceptable state $s_{\text {op/act }}$ (not a measure) of quality $Q_{o}$ of operations $\boldsymbol{O}$ that is $\boldsymbol{s}_{\text {op/act }}\left(\boldsymbol{Q}_{o}\right)$ is defined by a set $\mathbf{S}_{\text {opt/accQv }}$ of quality vectors [ $\mathbf{S}_{\text {opt/acc }}(\mathbf{q}(\mathbf{f}))$ ] of optimal or acceptable states $\mathbf{s}_{\text {optacc }}(\mathbf{q}(\mathbf{f}))$ with regard to all significant qualities $\mathbf{q}(\mathbf{f}) \mathbf{e} \mathbf{Q}(\mathbf{f})$ of all significant factors $\mathbf{f} \mathbf{\epsilon} \mathbf{F}$ with regard to the purpose $\mathbf{P}$ with the threshold of significance $\mathbf{S}_{\min }\left(\Delta \mathbf{M}_{\mathbf{R o}}\right)$ in a situation described by significant states of nature $\mathbf{S N}$, if the measure of operation results is optimal of at least acceptable $\mathbf{O P T} / \mathbf{A C C}\left(\mathbf{M}_{\mathbf{R O}}\right)$. Formally, it is an ordered septet $\boldsymbol{s}_{\text {opt } / a c c}\left(\boldsymbol{Q}_{o}\right):=<$

OPT/ACC $\left(M_{R O}\right), P, S_{\min }\left(\Delta M_{R O}\right), F, Q(F), S_{\text {opt/accev }}, S N>$ where

- OPT/ACC $\left(\mathbf{M}_{\mathbf{R O}}\right)$, where $\mathbf{M}_{\mathbf{R o}}[\mathbf{P}, \mathbf{S}(\mathbf{Q}(\mathbf{F})), \mathbf{S N}]$ for all $\mathrm{s}(\mathrm{q}(\mathrm{f})) \in \mathrm{S}(\mathrm{Q}(\mathrm{f})), \mathrm{q}(\mathrm{f}) \in \mathrm{Q}(\mathrm{f})$, and $\mathrm{f}$ $\epsilon \mathrm{F}$ is a measure of the results of operations

- $\quad \mathbf{P}$ - the purpose of operations

- $\mathbf{S}_{\min }\left(\Delta \mathbf{M}_{\mathbf{R O}}\right)$ - the threshold of significance expressed as the minimal increment of $\Delta \mathbf{M}_{\mathbf{R O}}$

- $\quad \mathbf{F}$ - set of significant factors $\mathbf{f}$

- $\mathbf{Q}(\mathbf{F})$ - sets of significant qualities $q(f) \in Q(f)$ for all $f \in F$

- $\quad \mathbf{S}_{\text {opt/accQv }}-$ set of quality vectors $\left[\mathbf{s}_{\text {opt/acc }}(\mathbf{q}(\mathbf{f}))\right]$ of optimal or acceptable states $\mathrm{s}_{\text {opt/acc }}(\mathrm{q}(\mathrm{f}))$ for all $q(f) \in Q(f)$ and $f \in F$

- $\quad \mathbf{S N}$ - a set of significant states of nature (beyond the decision-maker's control)

In operations, qualities of factors that are physically intrinsic (naturally belonging) to them acquire relevance, significance or importance, materiality, utility value, and usefulness from the purpose and circumstances of operations in the light of the adopted criteria of effectiveness and efficiency. This occurs only when a factor becomes the bone of contention, subject to the will of competing decision makers, who perceive it as relevant to and significantly material for their endeavours. According to their perception, they project their power, which manifests itself as a "force field." There is always a limited range, radius, or sphere within which a will may be imposed by projecting one's power. The field encompasses the physical, political, and economic forces in society, business, administration, or military operations. Significant materiality of an entity is established when it becomes the center of intersecting forces in an equilibrium of demand and supply exerted by the competing entities. Changes to the said equilibrium result in changes of the price tag, not necessarily in monetary terms, of the contested entity until the equilibrium becomes restored at a different level. Qualities are of no utility value on their own merit when not subject to such forces.

\section{Measuring Quality in Operations}

Many ask how to measure quality. Such a question implies (a) a measure of quality can be developed, (b) it may be useful, and (c) the more of it the better. An objective answer to this question surprises people in the light of the amount of effort, time, and resources spent on developing a metric of quality. Here is an attempt to answer the question.

The materiality of factors is ultimately determined by the strategic concept of operations. In business, it is embodied in a business plan. It provides the framework for interpreting reality and assessing the significance of the impact of its different aspects. These aspects lend importance and 
materiality to any representation (information, data, and rules of reasoning and proceeding). This materiality again pervasively lends its weight to all aspects of quality requirements that pertain to the representations of the factors under consideration. However, the external view of quality at a higher level offers an indirect solution to the irresolvable problem of a direct composite measure of quality at its base level.

One can measure the impact of any aspect of quality on operations when

- the qualities are significant

- as long as operations serve a measurable purpose with quantifiable increments of purpose or its cost effectiveness as functions of the states of qualities of factors used.

The grand total of the increments accounts summarily for all changes of states of qualities; thus, it indirectly measures the changes summarily. Only the operation approach to quality offers a situation-specific, indirect, nevertheless composite measure of factors' quality, which, however, can be neither general nor direct (Principium 4).

\section{Taxonomy of Operation Factors as Variables}

\begin{tabular}{|c|c|c|c|}
\hline \multicolumn{4}{|c|}{$\begin{array}{c}\text { Table } 3 \text { Schema of hierarchical impact-focused } \\
\text { taxonomy of decision variables }\end{array}$} \\
\hline \multicolumn{4}{|c|}{ Categories of Decision Variables } \\
\hline \multicolumn{3}{|c|}{ Direct } & Indirect \\
\hline \multicolumn{2}{|c|}{ Primary } & Secondary & \\
\hline $\begin{array}{l}\text { Universally } \\
\text { Necessary }\end{array}$ & $\begin{array}{c}\text { Situation } \\
\text { Specific }\end{array}$ & $\cdots \cdots \cdot$ & \\
\hline ....... & ......... & & \\
\hline
\end{tabular}

A hitherto unchallenged universal taxonomy of decision variables suits informing and facilitates a rational prioritization of research and their examination for practical applications. It pertains to factors, states of their qualities, and the consequences of their changes (Principium 5).

Information qualities are only a subclass of qualities of any factors in operations, and both are again a subclass of variables in decision making. The same applies to their taxonomies. Thus, for the sake of brevity, keeping in mind the power of this abstraction, the universal hierarchical disjoint and impact or result-focused (by type - qualitative, quantitative, or both) taxonomy will be presented simply as taxonomy of variables in decision making. Table 3 schematically illustrates the defined taxonomy. It is binary, logically perfect, the strongest taxonomy of all. It is impact-focused because, except for the last subclass, changes of variables of each class result in outcomes that belong to a separate class of outcomes.

To facilitate comprehension, it is necessary to reemphasize that a variable, whether dependent or independent in decision making, may represent any significant factor and any significant quality of such factor in any operations, not only in informing.

\section{The universal hierarchical impact-focused taxonomy of sets of significant variables $V$}

1. Subdivides the universe of variables $\mathbf{V}$ into direct and indirect or subordinate variables.

a. A change from the previous state $\mathbf{s}_{\mathbf{p}}$ to the current state $\mathbf{s}_{\mathbf{c}}$ of a direct variable $\mathbf{s}(\mathbf{d v})$, where dv $\mathbf{\epsilon} \mathbf{D V} \subset \mathbf{V}$ immediately affects the decision situation itself, and/or the actions to implement the decisions made, and/or the results of operations, which implies that they change the value of the adopted measure of results of informing $\Delta \mathbf{M}_{\mathbf{R I}}$, formally: $\left(\mathbf{s}_{\mathbf{p}}(\mathbf{d v}) \neq \mathbf{s}_{\mathbf{c}}(\mathbf{d v})\right) \Rightarrow\left(\Delta \mathbf{M}_{\mathbf{R I}} \neq \mathbf{0}\right)$. 


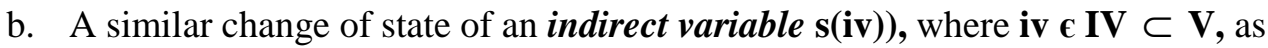
the name suggests, only indirectly affects the situation because it determines or contributes to states of other indirect variables of a higher order (closer to the direct ones and at the extreme equal to direct variables). When $\mathbf{s}_{\mathbf{p}}$ and $\mathbf{s}_{\mathbf{c}}$ denote, respectively, the previous state and the current state of an indirect variable, and $\mathbf{i} \mathbf{v}_{\mathbf{n}}$ and $\mathbf{i} \mathbf{v}_{\mathbf{n}-1}$ denote, respectively, indirect variables of $\mathrm{n}^{\text {th }}$-order and indirect variables of higher $(n-1)^{\text {th }}$-order [ for $n=1$ indirect variable of $0^{\text {th }}$-order is a direct variable $\mathbf{i \mathbf { v } _ { \mathbf { 0 } }}=\mathbf{d v}$ ]. It implies that a change of state of an indirect variable of $\mathrm{n}^{\text {th }}$-order causes a change of state of the related indirect variable of higher order $\mathbf{i}_{\mathbf{n}-1} \mathbf{v}$ or at the extreme of a direct variable.

Formally: $\left(\mathbf{s}_{\mathbf{p}}\left(\mathbf{i v _ { n }}\right) \neq \mathbf{s}_{\mathbf{c}}\left(\mathbf{i v _ { n }}\right) \Rightarrow\left(\mathbf{s}_{\mathbf{p}}\left(\mathbf{i v _ { n - 1 }}\right) \neq \mathbf{s}_{\mathbf{c}}\left(\mathbf{i v _ { n - 1 }}\right)\right)\right.$.

2. The direct variables it subdivides into direct primary and direct secondary variables. The primary ones are Boolean \{true, false \} they exist or not, and represent a requirement either met or not.

a. Changes to states of the direct primary variables $\mathbf{s}(\mathbf{d p v})$, where $\mathbf{d p v} \mathbf{c} \mathrm{DPV} \subset$ $\mathbf{V}$, always result in qualitative changes to the decision situations under consideration. Such changes result in adding or eliminating a variable from consideration, which is labeled $\Delta \mathbf{V}$. It must lead to a partial redefinition of the decision situation, which also has quantitative consequences. Formally: $\left.\left(\mathbf{s}_{\mathbf{p}}(\mathbf{d p v})\right) \neq \mathbf{s}_{\mathbf{c}}(\mathbf{d p v})\right)$ $\Rightarrow\left[\left(\mathbf{V}_{\mathbf{p}} \neq \mathbf{V}_{\mathbf{c}}\right)^{\wedge}\left(\Delta \mathbf{M}_{\mathbf{R I}} \neq \mathbf{0}\right)\right]$, where $\mathbf{V}_{\mathbf{c}}=\mathbf{V}_{\mathbf{p}}+\Delta \mathbf{V}$.

b. Changes to states of the direct secondary variables $\mathbf{s}(\mathbf{d s v})$, where dsv $\mathbf{\epsilon} \mathbf{D S V}$, mainly quantitatively change the results of operations; hence, they may not be significant $\left(\Delta \mathbf{M}_{\mathbf{R I}} \geq \operatorname{Min}\left(\Delta \mathbf{M}_{\mathbf{R I}}\right)\right)$. Nevertheless, if the subsequent quantitative changes reach a critical point - that is, if the current state $\mathrm{s}_{\mathrm{c}} \mathbf{c} \mathbf{C}(\mathbf{s}(\mathbf{d s v}))$ belongs to the set of critical states $\mathbf{C}$ - they may trigger a qualitative change of situations as well. Then they also become necessary. The secondary variables are mostly of a economic nature. If not only effectiveness but also economy of results matters, they also may be necessary, although not universally. Formally: $\left(\mathbf{s}_{\mathrm{p}}(\mathbf{d s v}) \neq \mathbf{s}_{\mathrm{c}}(\mathbf{d s v})\right) \Rightarrow\left[\left(\Delta \mathbf{M}_{\mathrm{RI}} \neq \mathbf{0}\right) \wedge\right.$ If $\left(\mathbf{s}_{\mathrm{c}}(\mathbf{d s v})\right.$ e $\mathbf{C}(\mathbf{s}(\mathbf{d s v}))$ then $\left.\left(\mathbf{V}_{\mathbf{p}} \neq \mathbf{V}_{\mathrm{c}}\right)\right]$

3. The direct primary variables it divides into those universally necessary versus the situation-specific necessary ones that are determined by the circumstances. Changes to their states are Boolean \{true, false $\}$ and always redefine the decision situation.

a. The direct universal primary variables are always necessary. Changes to their states $\mathbf{s}(\mathbf{d u p v})$, where dupv $\mathbf{\epsilon}$ DUPV $\subset \mathbf{V}$, add or eliminate them from consideration. Formally: $\left(\mathbf{s}_{\mathbf{p}}(\mathbf{d u p v}) \neq \mathbf{s}_{\mathbf{c}}(\mathbf{d u p v})\right) \Rightarrow\left(\mathbf{V}_{\mathbf{p}} \neq \mathbf{V}_{\mathbf{c}}\right)$

b. The direct primary situation-specific variables are also necessary; however, they are situation specific, and therefore necessary only under specific circumstances. Changes to their states $\mathbf{s}(\mathbf{d p s s v})$, where dpssv $\mathbf{\epsilon}$ DPSSV $\subset \mathbf{V}$, also add to or eliminate variables from consideration; however, only in specific situations. Formally: If (situation requires) then $\left(\mathbf{s}_{\mathbf{p}}(\mathbf{d p s s v}) \neq \mathbf{s}_{\mathbf{c}}(\mathbf{d p s s v})\right) \Rightarrow\left(\mathbf{V}_{\mathbf{p}} \neq \mathbf{V}_{\mathbf{c}}\right)$ (for instance, restricted availability of information in a competitive situation).

\section{Priorities in Research and Examination of Factors}

Once a point of reference and a universal hierarchical, result-determined taxonomy of variables have been defined, one can rigorously prioritize most of the research of factors in informing. First, one should investigate those variables that directly impact the informing situation, the implementation of informing, and, finally, the ultimate results of informing. Among the direct vari- 
Informing for Operations

ables, some certainly will be of a primary nature, which are always necessary (mandatory) and therefore universal. Other variables may also be necessary but only situation specific. The remaining direct variables are of a secondary nature. Changes of the direct primary variables always qualitatively and quantitatively change the outcomes. Changes to the direct secondary variables cause mainly quantitative changes to the outcomes; however, when the quantitative changes reach a critical point, they may cause qualitative changes as well.

Second, all the remaining variables are the very numerous indirect ones, which affect the outcomes only by way of the direct variables. Of course, there exist long chains of prerequisite and functional dependencies of the direct variables on the indirect ones of the first, second, and subsequent orders, which also suggests priorities of research. After an initial quantitative assessment of impact, one may prioritize them further by their materiality. Research about informing qualifies as applied science, and the findings of universal nature qualify as basic science.

With a well-defined point of reference, a frame of reference, and a yardstick, one may embark upon examination of how generally the qualities of factors may impact operations and whether some of them are universally necessary, hence quality requirements that are valid in all situations.

\section{Universal Operation Quality Requirements for Factors}

A considered factor must first be usable. To this end, it must meet at least seven universal quality requirements: (1) operation interpretable or recognizable, (2) operation relevant, (3) significantly material, (4) operation timely available, (5) operation spatially available, (6) actionably credible, (7) operation effective complete, and some situation-specific ones. The universality of quality requirements are easier to comprehend when one distinguishes examinations conducted (a) for the first time, and (b) routinely during regular operations. One may gain a better insight into operation quality of factors by analyzing situations when examiners face a factor not yet previously encountered and recognized.

\section{Operation Interpretable or Recognizable}

A factor in form (data, information) must be interpretable or, if in substance, recognizable by the using entity. To act discriminatorily, acting entities (humans or robots) must be capable of making some distinctions. Those distinctions are stored as arrays, vectors, graphs, images, patterns, or states of mind sm - members of the set SM. At least vectors (of states) must be considered because a single factor or a state of quality without a context cannot be interpreted. In robots, representation vector $\mathbf{r v}$ of states may trigger a designed sequence of state transitions. Pragmatically, it means that any received representation vector $\mathbf{r v}$ to be interpretable must match some (qualifier V) of the using entity's familiar states sm $\mathbf{\epsilon}$ SM, formally,

Definition 14: Operation interpretable or recognizable $r v \equiv \mathrm{V}[\mathrm{rv}=\mathrm{sm}]$ for all $\mathrm{sm} \epsilon \mathrm{SM}$

When the using entity (individual or device) is unable to interpret, identify, or recognize it, the factor must be excluded from further examination for practical purposes; however, it may be examined for research. In operations, operation interpretability of a factor in form in the diagnostic sequence is the first universal prerequisite for examining the remaining qualities of the factor.

\section{Operation Relevant}

Representation vector $\mathbf{r v}$ is a relevant factor $\mathbf{r f}$ if it matches some $(\mathbf{V})$ elements $r$ of necessary operation resources $\mathbf{R}(\mathbf{T})$. $\mathbf{R}(\mathbf{T})$ is the union $\bigcup$ of clusters of resources $\operatorname{cr}(\mathbf{t})$ necessary for all elementary tasks $\mathbf{t} \mathbf{\epsilon} \mathbf{T}$ in the network; the operations $\mathbf{O}$ can be decomposed as it is practiced by project management with PERT (Moder, Phillips, \& Davis, 1983): 
$\mathbf{R}_{\mathbf{O}}(\mathbf{T})=\operatorname{cr}\left(\mathbf{t}_{1}\right) \cup \operatorname{cr}\left(\mathbf{t}_{2}\right) \ldots \cup \operatorname{cr}\left(\mathbf{t}_{\mathbf{n}}\right)=\bigcup \operatorname{cr}(\mathbf{t})$ for all $\mathrm{t} \epsilon \mathrm{T}$, where $\mathrm{n}=$ cardinality of $\|\mathrm{T}\|$

Definition 15: Operation relevant factor $r v=\mathbf{r f}$, if $\mathrm{V}(\mathbf{r v}=\mathbf{r})$ for all $r \in \mathrm{R}_{\mathrm{O}}(\mathrm{T})$

In operations, operation relevancy of a factor in diagnostic sequence is the second universal prerequisite for examining the remaining qualities of the factor.

\section{Significantly Material}

In operations, one is interested in factors of significant materiality as in Definition 2. In operations, significant materiality of a factor in the diagnostic sequence is the third universal prerequisite for examining the remaining qualities of the factor.

Once the materiality of all factors is known, one may rank every specific factor $\mathbf{f}$ relatively to other factors by computing the ratio of its materiality over the sum of the absolute materiality $\mathbf{M ( f )}$ of all factors:

$$
\operatorname{Rank}(f)=\mathbf{M}(\mathbf{f}) / \sum|\mathbf{M}(\mathbf{f})| \text { for all } \mathrm{f} \in \mathrm{F}
$$

This implies that the sum of absolute ranks of factors equals 1, formally, $\sum|\operatorname{Rank}(\mathbf{f})|=\mathbf{1}$ for all $\mathbf{f}$ $\in$ F. Rank (f) stays within the range $0 \leq \operatorname{Rank}(\mathbf{f}) \leq 1$. The relative $\operatorname{Rank}(\mathbf{f})$ of the concerned factor $\mathbf{f}$ defines the maximum rank of every (qualifier $\boldsymbol{\Lambda}$ ) quality $q(f) \in Q(f)$ of this factor. Materiality plays a special role in all remaining qualities. It is central to all considerations where measurable effectiveness and efficiency matters in operations. It is the supreme quality within the entire universe of qualities (Principium 7).

The relative Rank (q(f)) of every quality $\mathbf{q ( f )}$ of the factor $\mathbf{f}$ cannot exceed the Rank (f) of the concerned factor, formally, $\Lambda[\operatorname{Rank}(\mathbf{q}(\mathbf{f})) \leq \operatorname{Rank}(\mathbf{f})]$ for all $q(f) \in Q(f)$

Here we see another universal principle. On the one hand, any factor derives its materiality from its qualities and the circumstances of its use. On the other hand, if one asks how important the factor's qualities are, one finds they cannot have higher materiality than the materiality of the factor, hence: In operations, each factor limits the upper materiality of its remaining qualities. As obvious as it may seem, many researchers conducting empirical studies have asked questions with no qualification of how users should rank different qualities of data by their importance. The answers to such questions are clearly task specific, and each quality of any factor cannot be ranked higher by importance than the factor by itself. It is not uncommon to disregard this principle. Unaware respondents rank relevance or materiality of factors lower than other qualities (Wang \& Strong, 1996). Conclusions drawn from such research cannot be reliable.

Among the significant factors F, one must distinguish two disjoint subsets of them: factors directly adding value or payoff avf $\epsilon \mathrm{AVF}$, and factors of indirect impact. The latter, however, if relevant, are indispensable for the effective use of the previous ones. They may be called necessary companions ncf $\epsilon$ NCF of factors adding value to operation results. The necessary companion factors also significantly impact the ultimate outcome. For instance, emergency calls for roadside assistance, which add a well-defined value to operation results, must be accompanied by information values about the location and some indispensable equipment or tools (necessary companions in substance) to provide the service. Without them, such calls cannot be effectively handled. Here again, another universal principle is evident: In operations, every factor directly adding value avf $\epsilon$ AVF confers its materiality upon its corresponding necessary companion factors ncf $\epsilon$ $\mathrm{NCF}$, or materiality $\mathrm{M}(\mathrm{avt})$ implies $\mathrm{M}(\mathrm{ncf}(\mathrm{avf}))$ that is the materiality of necessary companion factors ncf of the factor directly adding value avf.

$\Lambda[\mathbf{M}(\mathbf{n c f}(\mathbf{a v f}))=\mathbf{M}(\mathbf{a v f})]$ for all ncf $\epsilon$ NCF, avf $\epsilon$ AVF or

$\Lambda[\mathbf{M}(\mathbf{n c f}(\mathbf{a v f})) \Rightarrow \mathbf{M}(\mathbf{a v f})]$ for all ncf $\epsilon$ NCF, avf $\epsilon$ AVF 
Informing for Operations

Then the necessary companion factors $\mathbf{N C F}$ are the remaining factors of set $\mathbf{F}$; hence, NCF = F - AVF. These are principles of pervasiveness of materiality of factors on their corresponding qualities and their necessary companions.

Hence, one should be aware of the centrality, supremacy, and pervasiveness of materiality. Significant materiality or its cost effectiveness, if economy matters, is the central quality that ranks all the remaining significant qualities. It is the primary universally necessary quality that lends any factor the only sufficient reason to be considered in operations: It pervades other factors and their qualities (Principium 7).

\section{Operation Timely and Spatially Available}

Once decision makers have determined that they are dealing with a significant factor, they should ask whether it will be or can be made available

1. Timely before it loses its capacity to play its role, and

2. Spatially at the required location (at hand for a task).

To have a factor in substance timely and locally at hand when it is needed may be a logistic challenge. Even with a warning message to reach the addressees at their actual locations and on time may not be easy. If it is not possible, why bother about the remaining requirements? In everchanging reality, coincidence in time and space is of the essence. Even with all the remaining requirements met perfectly, if a factor is not available when and where it is necessary, its actual impact may become null.

In operations, timely and spatial availability of a factor in the diagnostic sequence are the fourth and fifth universal prerequisites for examining the remaining qualities of the factor.

\section{Actionably Reliable or Credible}

Significant factors must be tested for whether they can be actionably relied on; if credible, true. True means consistent with reality. Reliability refers to factors of substance and credibility to factors in form. Credibility of information values is a complex function of at least 20 indirect qualities (Gackowski, 2006a).

Since full credibility is rarely to never attainable, frequently users must act with only an acceptable level of credibility labelled actionably credible. For practical purposes, actionably credible can be defined as the degree of credibility at which the user is willing to take action. The definition is precise, but the actionable level of credibility is highly variable because it is a function of the decision situation, the circumstances of operations, and, in particular, the personality of the decision makers, whether they are risk avers or trigger happy.

In operations, actionable credibility or reliability of a factor in the diagnostic sequence is the sixth universal prerequisite for examining the remaining qualities of the factor.

Actionable credibility or reliability completes the list of the previously discussed universally necessary quality requirements for operation usability of any factor (operation interpretability, relevance, materiality, spatial availability, timely availability, and actionable credibility or reliability). In direct informing, when factors are directly accessible (with no intermediaries) to users, a factor is usable uf $\mathbf{\epsilon} \mathbf{U F}$ when it meets both the universally necessary quality requirements and the other situation-specific necessary quality requirements, such as the previously mentioned restricted availability (Principium 6). The set UF of usable factors is a subset of F, or, formally, uf $\mathbf{\epsilon} \mathbf{U F} \subset \mathbf{F}$. Usability of a factor does not imply its effective usefulness.

Definition 16: Usability $u f \equiv[\text { Operation interpretable(f) } \vee \text { Recognizable(f) }]^{\wedge}$ Operation relevant $\wedge^{\wedge}$ Significantly material(f) $\wedge^{\wedge}$ Operation spatially avail- 
able $^{\wedge}$ Operation timely available(f) ^[Actionably credible(f) v Actionably reliable(f) $]^{\wedge}$ meets all the situation-specific necessary quality requirements(f).

One should also notice how uncertainty about usability of factors affects decision situations. Uncertainty about factors' usability degrades decision situations (Principium 8). If usability

- is certain, the decision maker deals with a deterministic situation in the area affected by the factor.

- is only probable (the most likely case), the decision maker deals with a stochastic situation to the same extent as above.

- is not usable (for instance, not timely available or not actionable credible), the decision maker games to the same extent (even when operations are not triggered, because threats are ignored).

\section{Effectively Engageably Complete}

Once decision makers arrive at a set of usable factors, they must test them for completeness with regard to the tasks under consideration. In decision making, completeness of usable factors, in contrast to completeness of mapping data while storing, processing, and presenting them, is more complex than it appears on its surface. One must distinguish between at least two types of completeness: operation completeness and the never-attainable strategic completeness of usable factors. Within the context of decision situations, operation completeness of factors - ocf measures the degree to which the usable factors are available.

Effective completeness of clusters of resources required for each direct task may trigger its execution, which should generate effects equal to the materiality of the task. A task to be a direct task $\boldsymbol{d t}$, the complete task-specific cluster CUF(t) of usable factors uf must contain at least some (V) factor adding value avf to the results. Formally,

$$
\text { If } \left.\left\{\mathbf{V}\left[(\mathbf{u f} \boldsymbol{\epsilon} \mathbf{C U F}(\mathbf{t}))^{\wedge} \text { (uf } \mathbf{\epsilon} \operatorname{AVF}(\mathbf{t})\right)\right] \text { for all uf } \epsilon \operatorname{CUF}(\mathrm{t})\right\} \text { then } \mathbf{t}=\mathbf{d t}
$$

All operations (whether routine and repetitive or only one-time campaigns) may be decomposed into a network of tasks $\mathbf{t} \mathbf{\epsilon} \mathbf{T}$. There is at least one important degree of task-specific completeness: when it becomes sufficiently effective to determine a state transition in operations (to act or not). This is a matter of doctrine and policy. When economy of operations is secondary to operation effectiveness, one may be satisfied with only operation effective completeness. It pertains to operations conducted with an all-out effort, such as special operations or acts of terror according to their purpose, when economy is of secondary concern. The more of the direct task-specific factors are usable, the more effectively the tasks may be performed.

Formula 5 implies that a usable factor uf may actually be useful only when it is a member of some at least minimally operation effectively complete task-specific cluster of usable factors uf $\mathbf{\epsilon}$ $\mathbf{C U F}(\mathbf{t})$; otherwise, it is a resource in waiting. Hence, in operations, a useful factor uff $\mathbf{c}$ UFF $\subset$ UF $\subset \mathbf{F}$ is a usable factor that is a member of or engaged in some (V) at least minimally operation effectively complete clusters of usable factors in conducted direct tasks or their prerequisite tasks that trigger a direct one (Principium 10). Usefulness is never a distinguishing or defining attribute of anything. Usefulness is always contextual, never intrinsic to any entity.

Definition 17: A useful factor uff is a usable factor uf that is engaged in some effective operation complete conducted direct task or a prerequisite task that triggers the direct one t:

$\mathbf{V}[$ uf $\epsilon \operatorname{eoc}(\mathrm{t})] \Rightarrow(\boldsymbol{u} \boldsymbol{f}=\boldsymbol{u f f})$ for all $\operatorname{eoc}(\mathrm{t}) \in \mathrm{CUF}(\mathrm{t})$ and tasks $\mathrm{t} \in \mathrm{T}$. 
Operation effective completeness of usable factors closes the list of the seven universal direct primary necessary quality requirements for significant factors in operations. They are prerequisites for successful operations. Changes of states of respective qualities of operation factors result in qualitative and quantitative changes in the decision situations. Sometimes other additional situation-specific quality requirements are necessary, such as exclusive or restricted availability. Of course, completeness of even all the necessary known information about potential threats does not guarantee success when ignored by decision makers.

The diagnostic sequence in which the above direct primary quality requirements are presented has been obtained by examining which one "is a prerequisite of" another one. If no prerequisite relationship is found, then one should test the easier one first and then the other, more difficult, one in ascending order. Thus, the presented diagnostic sequence of examining the universal direct primary necessary qualities of operation factors seems to be a logical and the most economical one.

\section{When Economy of Operations Matters}

In most cases, economy of operations is an issue. To this end, one must test the economic level of its interpretability, operation spatial availability, operation timely availability, and actionable credibility or actionable reliability, and, ultimately, the operation effective completeness of the entire set of task-specific usable factors. Quantitative changes are additive; hence, the sequence of their examination seems irrelevant. When economy matters, an operation effective complete set of task-specific usable factors must be not only effective but also economically useful. Then the direct secondary qualities are necessary too (Principium 6).

Definition 18: An economically usable factor - euf must be first usable (uf - see Definition 16) and then must meet the direct secondary requirements described before, formally,

$e u f \equiv$ uf $^{\wedge}$ economically [(operation interpretable $v$ recognizable $)^{\wedge}$ operation timely available $^{\wedge}$ operation spatially available ${ }^{\wedge}$ (actionably credible $v$ reliable)].

None of the economic requirements can be ranked by importance, for they all are necessary now, hence equal. Thus, again, operation quality of factors cannot be summarily measured, but it can be accounted for by the difference in economy of operations when using factors of different quality and of different economy, which is a composite but only an indirect measure of quality.

In routine operations, the required state $\mathbf{r s}(\mathbf{q}(\mathbf{d}, \mathbf{t}))$ of quality $\mathbf{q}(\mathbf{d}) \mathbf{\epsilon} \mathbf{Q}(\mathbf{d})$ of data values $\mathbf{d} \mathbf{\epsilon} \mathbf{D}$ stored in common databases should be minimaxed. If the concerned factor $\mathbf{f}$ is a data value $\mathbf{d}$, hence $\mathbf{f}=\mathbf{d}$, the maximum of the minimal required state $\mathbf{r s}$ of quality $\mathbf{q}(\mathbf{d}, \mathbf{t})$ for each task $\mathbf{t} \mathbf{\epsilon} \mathbf{T}$, the data value $d$ is used and stored in common databases (for the most demanding task). Pursuing higher states of quality of usable operation factors than the minimaxed-required states implies a waste of effort. Formally, the minimaxed states for all $\mathbf{q}(\mathbf{d}) \mathbf{\epsilon} \mathbf{Q}(\mathbf{d})$ and $\mathbf{d}(\mathbf{t}) \mathbf{\epsilon} \mathbf{D}(\mathbf{t})$ are

$\operatorname{Minimaxed}(\boldsymbol{r s}(\boldsymbol{q}(\boldsymbol{d}, \boldsymbol{t})))=\max (\min (\mathbf{r s}(\mathbf{q}(\mathbf{d}, \mathrm{t})))$ for $\mathbf{s}(\mathrm{q}(\mathrm{d}, \mathrm{t})) \in \mathrm{S}(\mathrm{q}(\mathrm{d}, \mathrm{t})), \mathrm{q}(\mathrm{d}, \mathrm{t}) \in \mathrm{Q}(\mathrm{d}, \mathrm{t})$, and $\mathrm{t} \epsilon \mathrm{T}$

However, when the users of operation factors are separated from those who prepare them, the former may face difficulties with their interpretation and usage. They may be of different mindsets, cultural backgrounds, and conventions; speak different languages, etc. Thus, new aspects and problems of interpretability of factors emerge. Here again, we must distinguish two levels: interpretable and economically interpretable by indirect users as additional situation-specific quality requirements.

\section{The First Principia of Informing for Operations}

After the basics of the model have been presented, one may summarize the very first universal principles identified by studying the nature and role of informing for decision making in opera- 
tions, particularly those that operate as fundamental laws - denoted as principia. The model and definitions of operation quality requirements for information lead to the conclusion that they equally apply to factors in substance and in form, including their qualities represented by respective decision variables.

Components of the proposed framework and model for research in informing are anchored in formal definitions, basic assumptions, logical principles, and laws of nature. No general framework or model can be proven, but it can be tested, disproved, and refuted, as stated by Hume and restated by Popper in his Logic of Scientific Discovery (1959) (Magee, 2000, p. 115 and p. 223. They do not require empirical validation except for coming up with examples to the contrary; then a revision is unavoidable. The proposed model and framework, however, needs to be discussed, challenged, and criticized by the community of actual and potential researchers in informing. In other words, it needs their approval after all indispensable revisions have been made. If they remain unchallenged, they qualify as the results of basic research. This is so in contrast to applied research, which always remains situation specific.

For the universal principles - the principia, there are no exceptions in sight. Applicability and validity of most of them seems to reach far beyond operations conducted or only controlled by humans. Some of them apply equally even to activities and state transitions of all living entities. Hence, they should be of priority in research considerations, whether basic or applied, and helpful for doctoral dissertations pursuing results of lasting validity. They can be summarized as follows:

1. Without a point and frame of reference, one is lost. Teleological perspectivism and general relativity of observations (principium of absolute universality, if without "teleological"), measurements, and assessments applies to informing, operations, operations management, and decision sciences of purposive activities controlled by humans. In human-controlled operations, assessments are determined by the purpose and significant circumstances according to the selected criteria of effectiveness and/or efficiency of operations under the assumption that decision makers employ

- rational and rule-following choices, as defined by March (1994),

- with bounded rationality

○ as defined by Simon (1956) with regard to limitations of cognition, and

○ as proven by Kotarbinski (1961) that perfect rationality is unattainable,

- prevention of irrational choices, and

- automatic arbitration of choice uncertainty, as defined by Denning (2007).

2. Ultimately, there is no continuity. Operation factors, whether in substance or in form (information), are of quantum nature (principium of absolute universality). They are discrete or granular, including changes of their qualities. At the lowest end of their amount, a change cannot be less than the elementary amount of action - the Planck's constant.

With the emergence of nano-technology, quantum computing, and molecular bioengineering, we reach down to the naturally elementary. Otherwise, it may be an act of exchange of goods in economy, transaction in business, movement of a robot, human action, or change of the direction of the spin of an electron. With new technologies, the size of significant changes decreases precipitously. All communications are vulnerable to quality problems. If information is of serious impact, always verify. Communications are always subject to distortions (tapping, interfering, etc.) and bias (principium of absolute universality). Among living entities bias occurs

○ due to ignorance for communications received, and 
- due to both ignorance and purpose for communications sent.

Communications yield a broad spectrum of misinformation, with two extreme exceptions:

- $\quad$ Valid information - maps reality one to one, or

- $\quad$ Perfect disinformation - the reverse of valid information

Practically, one faces more frequently a less-than-perfect disinformation used to intentionally deceive. A perfect disinformation is too obvious to deceive entities informed. Deceptive or deceitful communication, besides misinformation, must contain one or more aspects of validity to be effective in deceiving. It applies to competitive environments except within willing alliances formed for higher competitiveness where bias due to purpose may not occur for internal communications.

4. Futile quests for a direct compound and useful metric of quality: All direct compound metrics of any group of factors' qualities are objectively impossible and useless.

By the law of teleological perspectivism and general relativity, all assessments, including assessments of qualities of factors, are always situation specific; hence,

- neither universal,

- nor materially of the same weight, or

- monotonically affecting possible measures of the results of operations due to the law of diminishing returns of their improvements.

It renders any direct compound metric of any group of qualities arbitrary, hence objectively impossible and useless. However, each individual quality, factor, or variable can be assessed separately by testing its impact on results.

5. In operations when purpose it measurable, the entire universe of qualities, factors, tasks, and decision variables that represent them can be universally classed ordered by the way they affect decision situations and the results of operations.

5.1. All of them classed into direct and indirect ones, the direct into primary necessary and secondary, the necessary into universally necessary and situation-specific necessary.

5.2. The universally necessary into interpretable and unrecognizable, the interpretable into relevant and irrelevant, the relevant into significant or insignificant, the significant into timely available or not, the timely available into spatially available or not, the available into actionably reliable or not. In addition, the actionable reliable may be required to meet situation-specific necessary requirements, which jointly makes them usable, otherwise they remain unusable.

5.3. The usable into effectively or efficiently engageably complete for operations. Within each class they may be correspondingly ordered or ranked by their materiality or efficiency.

5.4. The indirect ones into those of the first, second, and subsequent orders by the distance in the chains of dependencies from which they affect the direct ones.

Such a hierarchical impact-focused taxonomy automatically prioritizes their examination for research and practical applications.

6. The necessary qualities determine usability of each factor. Usability of each operation factor, whether in substance or in form (symbolic representations), is determined by the necessary quality requirements (principium of absolute universality) that are 
- primary universally necessary, or/and

- secondary necessary, if economy matters for instance, or/and

- $\quad$ situation-specifically necessary; for instance, exclusively available only to one entity

6.1. Primary universally necessary quality requirements are

- operation recognizable (for factors of substance) or operation interpretable (for factors in form - symbolic representations)

- operation relevant

- significantly material

- operation timely available

- operation spatially available

- actionably reliable for factors of substance and credible (for factors of substance)

6.2. Secondary necessary quality requirements usually are related to economy of costefficient operations. To this end, one must test the economic level of its

- operation interpretability,

- operation timely availability

- operation spatial availability,

- actionable credibility or actionable reliability, and, ultimately, and

- operation effective completeness of corresponding sets of task-specific usable factors.Centrality, supremacy, and pervasiveness of materiality. Significant materiality or cost effectiveness of factors, if economy matters, is the central supreme quality that ranks all the remaining significant qualities (principium of absolute universality, if materiality is limited only to degrees of significance). It is the primary universally necessary quality that lends every factor the only sufficient reason to be considered in operations: It pervades other factors and their qualities. If not only effectiveness, but also economy matters, one must consider efficiency or cost effectiveness of significant materiality instead of its original value. It is the central concept in informing for operations, as it should be in MIS.

7.1. Qualities acquire their materiality from the purpose and circumstances of operations.

7.2. Factors acquire materiality from their significantly material qualities or lend it to their respective other qualities.

7.3. Materiality of a factor limits materiality of its remaining qualities.

7.4. Factors lend their materiality to their necessary companion factors in operations.

An insignificant factor is also insignificant unless any of its qualities acquires significant materiality on its own merit and lends it to the attributing factor.

8. Uncertainty about factors' usability degrades decision situations. If usability

8.1. is certain, the decision maker deals with a deterministic situation in the area affected by the factor.

8.2. is only probable (the most likely case), the decision maker deals with a stochastic situation to the same extent as above. 
8.3. is not usable (for instance, not timely available or not actionable credible), the decision maker games to the same extent (even when operations are not triggered, because threats are ignored).

9. The dichotomous nature of the available and not-yet-available, data - the given and information - the communicated change (principium of absolute universality) in decision making refutes the existing fuzziness with regard to them as disjoint sets of entities.

9.1. Replacements of any available factor in substance, available factors in form such as data, or received symbolic representations of reality of a zero amount of information never change decision situations.

9.2. Quantitative change of any known factor in substance or routine information that communicates a quantitative change of known symbolic representations of reality - factors in form of a non-zero amount of information only quantitatively change decision situations unless the quantitative change reaches a critical point, causing qualitative changes of decision situations (realm of operational and tactical management).

\subsection{Unrecognized significantly material factors in substance or non-routine information} about significant, not-yet-recognized elements of reality always qualitatively and quantitatively change decision situations. They are the realms of strategic management.

10. Factors are useful only if used.. Factors are useful or are of realized usefulness only if they are (principium of absolute universality)

- usable and

- operation effectively complete and engaged in a conducted direct task or a prerequisite task that triggers the direct task.

Otherwise, they are usable factors in waiting.

Other principles of lesser importance within the context of the model of informing for operations that are also not recognized in literature, such as

1. the equivalency of materiality of lost, unavailable, or inaccessible data and information that represents the same entity.

2. the economic postulate of minimaxed quality of factors stored in common warehouses or databases for different tasks (see Formula 6).

\section{Conclusion}

The presented model entails fundamental concepts, basic distinctions, universal quality requirements, a universal taxonomy of informing factors, their qualities, and how to prioritize their examination for research and practical applications, with a summary of the first identified principia. They apply equally to factors in substance and factors in form, such as data and information, including qualities represented by decision variables. There seem to be no exceptions in sight.

Of the ten principia, with exceptions of the fourth and eighth, eight seem to apply at least partially to activities and state transitions occurring with living entities, even individual living cells, not only to operations controlled by humans. The former have been marked as candidates for principia of absolute universality. They deserve careful consideration in research, whether basic or applied, and in doctoral dissertations. If they remain unchallenged, they will stand forever as the results of basic, in contrast to applied research, always situation specific. Of the eight official and four peer reviewers, none challenged them with regard to their substance when discounting com- 
ments about the language. This paper is presented to elicit challenge, critique, discussion, and suggestions to develop a mutual consensus among those dealing with informing.

\section{References}

Cohen, E. (1999). Reconceptualizing information systems as a field of the transdiscipline informing science: From ugly duckling to swan. Journal of Computing and Information Technology, 7(3), 213-219. See: http://inform.nu/WhatsIS.htm

Denning, P. J. (2007). The choice uncertainty principle. Communications of the ACM. 50(11), 9-14.

Diminishing returns. (2007). Encyclopedia Britannica. Retrieved November 27, 2007, from Encyclopedia Britannica Online: http://search.eb.com/eb/article-9030471

Fisher, L., Chengalur-Smith, S., \& Wang, R. (2006). Introduction to information quality. Cambridge, MA: MIT Information Program

Gackowski, Z. J. (2004). Logical interdependence of data/information quality dimensions - A purposefocused view on IQ. Proceedings of the Ninth International Conference on Information Quality (ICIQ04), November, 5-7, 2004, Cambridge, MA.

Gackowski, Z. J. (2005a). Informing systems in business environment: A purpose-focused view. Informing Science Journal, 8, 101-122. Retrieved from http://inform.nu/Articles/Vol8/v8p101-122Gack.pdf

Gackowski, Z. J. (2005b). Operations quality of information: Teleological operations research-based approach, call for discussion. Proceedings of the 10th Anniversary International Conference on Information Quality-ICIQ-05, November, 4-6, 2005, Massachusetts Institute of Technology (MIT), Cambridge, MA.

Gackowski, Z. J. (2006a). Quality of informing: Credibility - Provisional model of functional dependencies. Proceedings of the 2006 Informing Science and IT Education Joint Conference, Salford, UK, June 25-28, 2006. Retrieved from http://proceedings.informingscience.org/InSITE2006/IISITZbig250.pdf

Gackowski, Z. J., (2006b). Quality of informing: Disinformation and bias - Philosophical background and roots. Journal of Issues in Informing Science and Information Technology, 3, 731-744. Retrieved from http://informingscience.org/proceedings/InSITE2006/IISITZbig250.pdf

Gackowski, Z. J. (2007a). A formal definition of operation quality of factors - A focus on data and information. International Journal of Information Quality, 1(2), 225-249.

Gackowski, Z. J. (2007b). Informing as a discipline: An initial proposal. Proceeding of the Informing Science + IT Education Joint Conference InSITE 2007, University of Ljubljana, Slovenia, June 21 - 24, 2007. Retrieved from http://proceedings.informingscience.org/InSITE2007/InSITE07p187208Gack346.pdf

Hamlyn, D. W. (1980). Schopenhauer: The arguments of philosophers. London, UK: Routeledge \& Kegan Paul.

Huang, K., Lee, Y. W., \& Wang, R. Y. (1999). Quality information and knowledge. Upper Saddle River, NJ: Prentice Hall

Ives, B., Hamilton, S., \& Davis, G. B. (1980). A framework for research in computer-based management information systems. Management Science (pre-1986), Sep 1980, 26, 9.

Kotarbinski, T., (1961). The property of a good plan. Methodos, 13, 189-201.

Lee, Y. W., Pipino, L. L., Funk, J. D., \& Wang, R. Y. (2006). Journey to data quality. Cambridge, MA The MIT Press.

Magee, B. (2000). The great philosophers: An introduction to Western philosophy. Oxford, UK: Oxford University Press.

March, J. G. (1994). A primer on decision making - How decisions happen. New York: Free Press. 
Informing for Operations

Mazur, M. (1970). Jakosciowa teoria informacji [Qualitative theory of information]. Warsaw, Poland: Panstwowe Wydawnictwa Techniczne (PWT).

Mende, J. (2005). The poverty of empiricism. Informing Science Journal, 8, 189-210. Retrieved from http://inform.nu/Articles/Vol8/v8p189-210Mende.pdf

Peirce, C. S. (1958). Collected papers of Charles Sanders Peirce [8 vols.]. Cambridge, MA.

Planck's constant. (2007). Encyclopedia Britannica. Retrieved November 26, 2007, from Encyclopedia Britannica Online: http://search.eb.com/eb/article-9060293

Shannon, C. E., \& Weaver, W. (1949). The mathematical theory of communication. Urbana, IL: University of Illinois Press.

Simon, H. A., (1956). Rational choice and the structure of the environment. Psychological Review, 63(2), 129-138.

Wang, R. Y., \& Strong, D. M. (1996). Beyond accuracy: What data quality means to data consumers, Journal of Management Information Systems (JMIS), 12(4), 5-34.

\section{Biography}

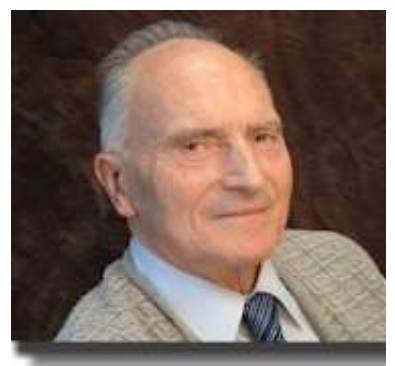

Zbigniew J. Gackowski has experience in industry, administration, and academia. It bridges his Central European and US experience in Computer Information Systems (Warsaw Polytechnic, University of Michigan [Fulbright Research Scholar], Purdue University [Visiting Associate Professor], Baruch College [Visiting Professor], California State University, Stanislaus [Professor], and the University of Melbourne [Visiting Professor]). In Poland, he has published 120 items (four books and six papers in refereed journals) and has presented 12 papers in Europe, the US, Middle-East, and South America. In the

USA, he has taught at three universities and has presented 26 research papers that have been published in the proceedings of ASIS, ACM, DSI, Information Systems Educators Conference, The Informing Science Institute, and the International Conference on Information Quality at MIT. He is a member of ACM and DSI, a charter member of the Association for Information Systems, and a founding member of the Institute of Informing Science. His research focuses on quality of data, information, and informing from the perspective of decision making in operations. 